\title{
FOLGA ORGANIZACIONAL NO PROCESSO DE GESTÃO DO ORÇAMENTO: UM ESTUDO NO SENAC DE SANTA CATARINA
}

\author{
Ilse Maria Beuren \\ ilse.beuren@gmail.com \\ Universidade Federal do Paraná - Curitiba, PR / Brasil \\ Paulo Wienhage \\ pwienhage@hotmail.com \\ Universidade Regional de Blumenau - Blumenau, SC / Brasil
}

Recebido em 24/11/2012

Aprovado em 22/03/2013

Disponibilizado em 01/08/2013

Avaliado pelo sistema double blind review

Revista Eletrônica de Administração

Editor: Luís Felipe Nascimento

ISSN 1413-2311 (versão on-line)

Editada pela Escola de Administração da Universidade Federal do Rio Grande do Sul.

Periodicidade: Quadrimestral

Sistema requerido: Adobe Acrobat Reader.

\section{RESUMO}

A folga organizacional no processo orçamentário tem recebido atenção de pesquisadores e gestores em vista de possíveis conflitos de interesses entre principal e agente. Neste sentido, o estudo objetiva identificar a propensão de criar folga organizacional no processo de gestão do orçamento pelos Gestores das Unidades de Negócios do SENAC de Santa Catarina. Pesquisa descritiva, com abordagem quantitativa, foi realizada por meio de uma survey. A população da pesquisa compreende os 21 Gestores das Unidades Operativas do SENAC de Santa Catarina. Um questionário foi encaminhado no mês de julho de 2010, sendo que a amostra constitui-se dos 15 respondentes da pesquisa. O instrumento de coleta de dados consistiu de um questionário traduzido da pesquisa de Onsi (1973), composto por 42 questões fechadas, envolvendo escala Likert, com fatores de oito dimensões da prática da gestão do orçamento, focalizando a folga orçamentária. Os dados foram importados para o software estatístico SPSS versão 13, para fins de análise dos elementos de folga por meio de estatística descritiva, do Alfa de Cronbach e da técnica de análise fatorial. Os resultados do estudo indicam que os gestores têm propensão para criar folga em seus orçamentos, apesar do SENAC não remunerar seus gestores com base nos resultados, o que por si só deveria ser um fator que não motiva a criação de folga orçamentária. Diferente da pesquisa realizada por Onsi (1973), no SENAC os motivos para a criação de folga orçamentária decorrem do interesse dos gestores em apresentar desempenho superior em relação ao previsto no orçamento.

Palavras-chave: Folga organizacional; Folga orçamentária; Gestão do orçamento; Gestores das Unidades Operativas; SENAC/SC.

\section{ORGANIZATIONAL SLACK IN THE BUDGET MANAGEMENT PROCESS: A STUDY OF SENAC IN SANTA CATARINA}

REAd I Porto Alegre - Edição 75 - N 2 - maio/agosto 2013 - p. 274-300 


\begin{abstract}
The organizational slack in the budget management process has received attention from researches and managers in view of possible conflicts of interest between principal and agent. In this sense, this study aims to identify the propensity to create organizational slack in the budget management process by the SENAC's Managers of Business Units of Santa Catarina. Descriptive research with quantitative approach was conducted through a survey. The survey includes 21 SENAC's Managers of Operating Units of Santa Catarina. A questionnaire was sent in July 2010, and the sample is consisted of 15 survey respondents. The instrument for data collection consisted of Onsi's (1973) research translated questionnaire, composed of 42 closed questions, involving Likert scale, with factors of eight practice dimensions of budget management, focusing on budgetary slack. The data were imported into SPSS statistics software, version 13, for analysis of the elements of slack through by descriptive statistics, Cronbach's Alpha and of the technique of factor analysis. The study results indicate that managers have a propensity to create slack in their budgets, although SENAC does not compensate their managers based on the results, which should not be a factor that motivates the creation of budgetary slack. Unlike the survey conducted by Onsi (1973), in the SENAC the reason for the creation of budgetary slack is a result of managers interest to deliver superior results related to what was included in the budget.
\end{abstract}

Keywords: Organizational slack; Budgetary slack; Budget management; Managers of Operating Units; SENAC / SC.

\title{
INTRODUÇÃO
}

As empresas utilizam o orçamento para o planejamento e controle de suas atividades operacionais. Onsi (1973) esclarece que, conseqüentemente, o orçamento representa um importante instrumento de gestão para a previsão do futuro das organizações. O autor destaca que há basicamente dois motivos que podem gerar falhas no processo de planejamento orçamentário, o primeiro devido a uma imprecisão dos dados apurados (erro) e o segundo pela concepção dos gestores em criar folga orçamentária.

A folga orçamentária tem sido um importante foco de investigação. A literatura sobre folga organizacional mostra que os gestores têm motivos para desejar operar em um ambiente de folga (ONSI, 1973; MERCHANT, 1985; YOUNG, 1985; DUNK, 1993; STEVENS, 2002; STALEY e MAGNER, 2007). As investigações sobre folga orçamentária consideram o orçamento como a personificação deste ambiente e, portanto, assume que os gestores usarão o processo de construção do orçamento como instrumento para conseguir folgas orçamentais (RIAHI-BELKAOUI, 1994).

Estudos anteriores buscaram identificar o impacto da folga orçamentária no desempenho das organizações. A construção de folga em um orçamento significa a escolha de um padrão que possa mais facilmente ser atingível e o comportamento que gera folga orçamentária pode ser influenciado também pelo sistema de avaliação. Os gestores não são 
Folga organizacional no processo de gestão do orçamento: um estudo no SENAC de Santa Catarina

motivados necessariamente pela maximização do lucro da empresa, podem ter motivações que visem o interesse próprio. Este interesse próprio dos gestores pode se revelar com um olhar individual em detrimento do todo no processo de gestão do orçamento das empresas.

A inclinação dos gerentes de departamentos em criar folga orçamentária tem o potencial de comprometer a eficácia do sistema orçamentário da entidade. Esta é uma condição em que os custos orçados, receitas ou volumes de produção são mais fáceis de serem atingidos, minando a eficácia do orçamento como uma ferramenta de planejamento organizacional e de controle (STALEY; MAGNER, 2007).

A criação de folga pode ocorrer independentemente se a organização está baseada em uma estrutura centralizada ou descentralizada de unidades de negócios. Em unidades descentralizadas de negócios, os gestores têm sob sua responsabilidade a gestão do orçamento e devem ter sistemas de controle que forneçam à alta administração informações, no que diz respeito à rentabilidade e desempenho de suas operações, de forma que suas decisões e ações sejam consistentes com os objetivos globais da organização (OLIVEIRA; ÁVILA, 1999).

Onsi (1973) foi o primeiro autor a pesquisar empiricamente as conexões entre o sistema orçamentário e a propensão para criar folga orçamentária. O autor constatou que 80\% dos gerentes que entrevistou afirmaram introduzir folgas no orçamento. Segundo Wu (2006), quando o orçamento é tratado com a devida importância que merece por parte da direção das empresas, há redução da assimetria de informações, porém, ainda assim os orçamentos podem apresentar pequenas folgas.

Uma inquietação, decorrente da análise de estudos sobre a criação de folga organizacional no processo de gestão do orçamento, é se em organizações que não adotam o sistema de remuneração variável para os executivos isso também ocorre. Se o conflito de interesses entre principal e agente e a assimetria de informações entre ambos tendem a sobrepor os interesses do agente aos do principal, parece razoável pensar que em uma organização que não possui sistema de recompensa variável para os colaboradores, a criação de folga no orçamento seria minimizada.

Desta forma, esta pesquisa busca responder a seguinte questão-problema: Qual a propensão de criar folga organizacional no processo de gestão do orçamento pelos Gestores das Unidades de Negócios do Serviço Nacional de Aprendizagem Comercial (SENAC) de Santa Catarina? Assim, o objetivo que norteia este estudo é identificar a propensão de criar folga organizacional no processo de gestão do orçamento pelos Gestores das Unidades de Negócios do SENAC de Santa Catarina. 
A pesquisa justifica-se pela sua contribuição ao desenvolvimento e ampliação da investigação sobre folga organizacional. A análise da folga organizacional no processo de gestão do orçamento, ainda que restrita a modalidade de folga orçamentária, deve merecer atenção no que concerne a identificação dos elementos com maior propensão a sua criação. A relevância da pesquisa é destacada por transcorrer em uma organização que não adota sistema de remuneração variável para os gestores, diferenciando-a de estudos, por exemplo, de Verhagem e Beuren (2011), que associaram a remuneração variável dos gestores com a criação de folga organizacional no processo de gestão do orçamento.

\section{REVISÃO DA LITERATURA}

\subsection{Folga Organizacional}

O conceito de folga organizacional tem se constituído num importante elemento da literatura. Os primeiros ensaios abordando o assunto iniciaram-se com Penrose (1959), ao atribuir que o crescimento organizacional estava intrinsecamente ligado à disponibilidade de folga organizacional. Cyert e March (1963) apresentaram sua concepção de folga organizacional, determinando que a folga é o composto de recursos disponíveis para a empresa acima do necessário para atender as suas necessidades imediatas. A folga representa a diferença entre os recursos existente e a demanda efetiva.

A folga organizacional, na concepção de Dimmick e Murray (1978) representa os recursos que uma organização tem e que não estão comprometidos com uma despesa necessária, e tais recursos poderão ser usados de forma discricionária. Nohria e Gulati (1996) definem folga organizacional como o conjunto de recursos disponíveis em uma organização que estão além do mínimo necessário para atender a um determinado volume de produção. Geiger e Cashen (2002) ampliam a definição de Nohria e Gulati (1996), destacando que a folga representa os recursos disponíveis de uma organização que excedem a necessidade mínima de produção para atender as expectativas de resultados dos gestores.

Sender (2004, p. 4) apresenta uma conceituação diferente de folga organizacional. A autora menciona que, "uma vez que nem sempre as organizações otimizam seus recursos, estas acumulam recursos reservas e oportunidades não exploradas que se transformam em um colchão contra tempos ruins". Cita ainda que, "apesar do colchão nem sempre ser premeditado, a folga produz um desempenho mais regular, reduzindo tal colchão em tempos bons e melhorando-o em tempos ruins". 
Folga organizacional no processo de gestão do orçamento: um estudo no SENAC de Santa

Catarina

Depreende-se que não há uma definição consensual do que efetivamente represente a folga organizacional, mas o assunto constitui-se em um tema de interesse de pesquisadores. A definição mais aceita para folga organizacional é a de Bourgeois (1981, p. 30), como sendo "aquele colchão de recursos efetivos ou potenciais que permitem a uma organização adaptarse com sucesso às pressões internas de ajustes ou às pressões externas por mudanças em políticas, assim como iniciar mudança em estratégias com respeito ao meio ambiente".

No que concerne aos recursos de folga organizacional, Lima (2008) destaca que a folga organizacional é gerada a partir de diferentes formas, incluindo excesso de empregados, capacidade não utilizada e despesas de capital não necessárias. Durante o processo normal de crescimento da empresa, folga ou o excesso de recursos deve aparecer, sendo então necessário que os gestores saibam como gerenciar esse excesso.

Pesquisas sobre folga organizacional comprovam esta relação, pois têm identificado excesso de mão-de-obra nas organizações, capacidade produtiva ociosa, representando custos de capital desnecessários, o que resulta em desvantagens competitivas e redução de desempenho (CYERT e MARCH, 1963; BOURGEOIS, 1981; SINGH, 1986). Por outro lado, quando a administração da empresa tem conhecimento e consegue mensurar esta folga, pode utilizar melhor os recursos disponíveis, criando vantagens competitivas e otimizando o desempenho (RUST; KATZ, 2002).

Apesar das diferentes modalidades de folga organizacional apresentadas, a folga de recursos geralmente é demonstrada através de indicadores financeiros, usando-se a definição básica fornecida por Bourgeois (1981). Outros pesquisadores, por exemplo, Cheng e Kesner (1997) e Herold, Jayaraman e Narayanaswamy (2006), apontam três tipos de folga de recursos: folga disponível, a recuperar e potencial.

A folga disponível é constituída de recursos que ainda não estão comprometidos com a estrutura organizacional ou com despesas específicas, como exemplo pode-se citar o excesso de liquidez. Já a folga a recuperar é constituída de recursos que já foram absorvidos pela atividade operacional, mas que podem ser recuperados pela redução, reavaliação, de algumas despesas, exemplo o excesso de despesas gerais. E, finalmente, a folga potencial, que poderá ser constituída por um aumento do capital próprio (CHENG e KESNER, 1997; HEROLD, JAYARAMAN e NARAYANASWAMY, 2006).

Segundo Cheng e Kesner (1997), para a maioria dos gestores o termo folga evoca uma série de percepções negativas, pois é vista como um custo desnecessário para as organizações, os gestores buscam adequar os seus negócios de forma a eliminar qualquer folga. Porém a 
folga prevê recursos para a inovação e mudança, aumentando, assim, a capacidade da empresa para adaptar-se às mudanças ambientais e melhorar o desempenho de longo prazo (CYERT e MARCH, 1963; MOHR, 1969).

Os recursos de folga organizacional são classificados por Sender (2004) em: a) recursos humanos, dizem respeito ao número de pessoas ou de horas de trabalho além do mínimo necessário; b) recursos físicos, referem-se à capacidade de máquinas, disponibilidade de matéria-prima ou outros recursos além do mínimo necessário; c) recursos financeiros, abarcam recursos em espécie ou líquidos além do suficiente para uso imediato não previsto.

Schiff e Lewin (1970) e Onsi (1973) abordam outro elemento de folga organizacional, que é o orçamento além do mínimo necessário, caracterizando-o como folga orçamentária. De certo modo, a folga orçamentária passa a ser um campo de estudo da folga organizacional, que pode implicar excesso de recursos humanos, físicos e financeiros no processo orçamentário de uma organização.

\subsection{Gestão e Controle da Folga Orçamentária}

A elaboração e acompanhamento do orçamento representam um sistema de controle importante para as organizações. Ishisaki (2003) destaca que o orçamento não é uma técnica a parte que pode ser utilizada independente do processo administrativo. Welsch (1983) explica que o orçamento envolve várias abordagens, técnicas de administração, previsões de receitas, despesas, estoques, planejamento organizacional, planejamentos de recursos humanos e controle de custos.

Tung (1983, p. 32) esclarece que "em todas as situações de implantação, operação e controle orçamentário, o elemento humano é uma condição básica". O autor também destaca que os colaboradores quando percebem que o sucesso da empresa também é de responsabilidade deles, faz com que estes tenham mais vontade de colaborar. No entanto, Welsch (1983, p. 46) evidencia que o planejamento orçamentário da empresa deve apresentar metas atingíveis e, ao mesmo tempo, que se constituam em um desafio para a empresa, "o plano deve ser elaborado com a convicção de que a empresa atingirá ou excederá todos os objetivos importantes".

Dentro do contexto de orçamento, o controle é um ponto importante a ser considerado. Segundo Welsch (1983, p. 41), "podemos definir o controle como sendo simplesmente a ação necessária para verificar se os objetivos, planos, políticas e padrões estão sendo obedecidos”. O controle orçamentário, conforme Ishisaki (2003) é elaborado mediante o confronto entre os valores planejados e realizados. Braga (1995) corrobora e expande este conceito ao 
Folga organizacional no processo de gestão do orçamento: um estudo no SENAC de Santa Catarina

determinar que há necessidade de se investigar as causas determinantes das variações ocorridas entre os dados reais e orçados, e implementar ações corretivas.

A confrontação dos resultados reais com os planejados é uma forma de controle. Certos dados históricos também podem ser utilizados como parâmetros de medida para um melhor controle futuro (WELSCH, 1983). Esta idéia é reforçada por Ishisaki (2003), ao defender que um sistema de controle orçamentário deve ser baseado em um sistema de relatórios que possibilite mostrar as variações entre os dados reais e orçados. Welsch (1983) menciona que o cumprimento ou não dos objetivos deve ser percebido e controlado durante o período de execução, e não apenas no final, pois então já é tarde para medidas corretivas.

Portanto, para que a gestão do orçamento se torne eficaz é necessário estabelecer formas de controle, a fim de verificar se os objetivos estão sendo atingidos. Caso estes não estejam ocorrendo da forma planejada, é importante o gestor saber disso em tempo hábil para que possa tomar as medidas necessárias.

Empresas que possuem sistema de informação não bem estruturado, aliado a falta de comunicação interna, cujos objetivos e metas não são claramente estabelecidos, apresentam tendência a gerar folga orçamentária (JUNQUEIRA; OYADOMARI; MORAES, 2010). De acordo com Linn et al. (2001), não há motivos para haver folga organizacional quando a empresa tem um adequado sistema que gere as informações necessárias ao controle.

O conceito de folga orçamentária, segundo Nascimento, Ribeiro e Junqueira (2008), é derivado dos estudos de folga organizacional. O orçamento forma uma parte importante do desempenho de avaliação para gerentes e diretores das organizações. O comportamento humano sugere que os participantes no processo orçamentário criem folgas orçamentárias com o objetivo de facilitar o alcance das metas, onde os objetivos são cumpridos e ultrapassados (NASCIMENTO, 2006).

O sistema de orçamento tem sido evidenciado devido à propensão dos gestores em criar folga orçamentária. Neste sentido esta propensão tem sido aumentada ou diminuída pela forma que o sistema orçamentário é gerido (RIAHI-BELKAOUI, 1994). Onsi (1973) identificou, através de evidências empíricas, que os gestores influenciam o processo de orçamento por meio de manipulações das peças orçamentárias, criando folgas em "bons anos" e convertendo-as em lucros nos "anos ruins", principalmente quando o orçamento serve como base para avaliação de desempenho.

Atkinson et al. (2011) salientam que os indivíduos desempenham um importante papel na elaboração do orçamento, e que em virtude disso podem surgir questões comportamentais, 
visando o benefício próprio. Baiman e Lewis (1981) destacam que o orçamento pode estar vinculado ao processo de avaliação de desempenho e que muitas vezes o planejamento orçamentário representa um sistema de incentivos salariais, ocasionando a manipulação das projeções orçamentárias, o que incentiva a folga orçamentária.

A folga no orçamento varia ao longo do tempo e de empresa para empresa. Schiff e Lewin (1970) identificaram em suas pesquisas folga de $20 \%$ a $25 \%$ nas despesas operacionais do planejamento orçamentário de algumas instituições. Os autores verificaram que os gestores tendem a construir folga orçamentária para satisfazer aspirações pessoais, manipulando os resultados em períodos de crise.

Quando é introduzida uma folga orçamentária, que ocorre quando o indivíduo superestima despesas e custos e subavalia receitas, no intuito de facilitar o alcance de suas próprias metas, esta afeta negativamente os processos de planejamento e orçamento através do viés da alocação ou utilização de recursos (LUKKA, 1988; NASCIMENTO, RIBEIRO e JUNQUEIRA, 2008).

Atkinson et al. (2011) recomendam um forte entrelaçamento entre o executivo que aprova o orçamento e os gestores que o elaboram, e que cada alteração no orçamento tenha uma justificativa adequada e pertinente. Salientam que isso é importante para evitar a manipulação do orçamento, como forma preventiva de evitar a folga orçamentária.

Infere-se que a folga organizacional no processo orçamentário pode ser criada por meio do excesso de recursos humanos, físicos e financeiros disponíveis, ou seja, recursos disponíveis além do mínimo necessário. Todavia, a folga organizacional também pode ser criada com elevado nível de participação dos gestores na elaboração do orçamento (LÓPEZ; STAMMERJOHAN; MCNAIR, 2007) e autonomia na tomada de decisões (INDJEJIKIAN; MATEJKA, 2006), caracterizada como folga de poder no processo orçamentário.

\section{MÉTODO E PROCEDIMENTOS DA PESQUISA}

Esta pesquisa caracteriza-se como descritiva, com abordagem quantitativa, e foi realizada por meio de uma survey. Segundo Cervo e Bervian (2006, p.66), pesquisa descritiva é "a pesquisa que observa, registra, analisa e correlaciona fatos ou fenômenos (variáveis) sem manipulá-los”. Gil (2008) destaca que uma das características mais significativas está na utilização de técnicas padronizadas de coletas de dados.

Pesquisas do tipo levantamento ou survey, de acordo com Gil (2008, p. 82), "se caracterizam pela interrogação direta das pessoas cujo comportamento se deseja conhecer". O autor explica que neste tipo de pesquisa "procede-se a solicitação de informações a um grupo 
Folga organizacional no processo de gestão do orçamento: um estudo no SENAC de Santa

Catarina

significativo de pessoas acerca do problema estudado para em seguida, mediante análise quantitativa, obter as conclusões correspondentes aos dados coletados”.

Sobre a abordagem quantitativa, Richardson (1989, p. 29) menciona que ela "é frequentemente aplicada nos estudos descritivos, naqueles que procuram descobrir e classificar a relação entre variáveis, bem como nos que investigam a relação de casualidade entre fenômenos".

A coleta dos dados desta pesquisa ocorreu junto aos Gestores das Unidades Operativas da instituição denominada de Serviço Nacional de Aprendizagem Comercial (SENAC) de Santa Catarina. A escolha da instituição foi intencional devido à acessibilidade para realizar a pesquisa. Trata-se de uma organização de ensino, de direito privado, sem fins lucrativos, administrada pela Confederação Nacional do Comércio (CNC) e que oferece serviços de educação profissional em todo território nacional (SENAC, 2009).

Compete ao Departamento Regional (DR) executar as medidas necessárias à observância das diretrizes gerais da ação do SENAC. O DR elabora as diretrizes estratégicas que deverão ser seguidas por todas as Unidades Operativas. As sete Faculdades, os onze Centros de Educação Profissional e os três Centros Especializados possuem, cada qual, sua autonomia administrativa, seu regimento e sua estrutura organizacional (SENAC, 2009).

Um questionário com perguntas fechadas foi encaminhado pelo google'docs no mês de julho de 2010 à população de 21 gestores, sendo que a amostra compreende os 15 respondentes da pesquisa, representando $71 \%$ da população. O instrumento de coleta de dados consiste de um questionário utilizado em uma pesquisa de Onsi (1973), composto por 42 questões fechadas, envolvendo escala Likert de cinco pontos, cuja escala varia entre "concordo totalmente" e "discordo totalmente". Este questionário possibilitou analisar fatores de oito dimensões da prática da gestão do orçamento, focando a folga orçamentária.

Após a coleta de dados, os dados foram tabulados em planilha do Microsoft Excel e importados para o software estatístico SPSS versão 13. Inicialmente fez-se a análise por meio da estatística descritiva com cálculo de freqüência delimitando-se a existência ou não dos elementos de folga organizacional objeto de estudo. Quanto maior a dispersão das respostas dentro de cada elemento, menor é a percepção da existência do mesmo. Os elementos que não foram indicados pelos respondentes foram retirados da análise.

Antes da aplicação da análise multivariada de dados, verificou-se a confiabilidade dos dados por meio do alfa de Cronbach. Em seguida, aplicou-se a técnica de análise fatorial. A análise fatorial, conforme Hair et al. (2009, p. 98), "é uma técnica de interdependência na qual 
Ilse Maria Beuren \&Paulo Wienhage

todas as variáveis são simultaneamente consideradas, cada uma relacionada com todas as outras, empregando ainda o conceito da variável estatística, a composição linear de variáveis”. O autor explica ainda que, utilizando-se da análise fatorial é possível analisar os dados por meio de um número menor de variáveis do que com todas as variáveis originais.

\section{DESCRIÇÃO E ANÁLISE DOS RESULTADOS}

\subsection{Perfil dos Respondentes}

No que concerne ao perfil dos respondentes, investigou-se a escolaridade e idade dos respondentes, bem como o tempo que trabalha na instituição objeto de estudo e o tempo na função de gestor. Assim, inicialmente perguntou-se a escolaridade e idade dos respondentes, cujos dados constam tabulados na Tabela 1.

Tabela 1 - Escolaridade e idade dos Gestores entrevistados

\begin{tabular}{lcc|ccc}
\hline \multicolumn{3}{c}{ Escolaridade } & \multicolumn{3}{c}{ Idade } \\
\hline & Respondentes & $\boldsymbol{\%}$ & & Respondentes & \% \\
\hline Graduação & 0 & 0,0 & Entre 30 e 39 anos & 5 & 33,3 \\
Pós Graduação Latu Sensu & 9 & 60,0 & Entre 40 e 49 anos & 6 & 40,0 \\
Pós Graduação Strictu Sensu & 6 & 40,0 & Acima de 50 anos & 4 & 26,7 \\
\hline \multicolumn{1}{c}{ Total } & $\mathbf{1 5}$ & $\mathbf{1 0 0 \%}$ & Total & $\mathbf{1 5}$ & $\mathbf{1 0 0 \%}$ \\
\hline
\end{tabular}

Fonte: dados da pesquisa.

Observa-se na Tabela 1 que todos os Gestores das Unidades de Negócios tem formação em nível de pós-graduação. Nota-se também que a faixa etária predominante situase entre 40 e 49 anos e que todos possuem acima de 30 anos de idade.

Ainda sobre o perfil dos respondentes da pesquisa, perguntou-se sobre o tempo que trabalham na organização e o tempo que exercem a função de Gestor de Unidade de Negócios do SENAC/SC, conforme demonstrado na Tabela 2.

Tabela 2 - Tempo na organização e tempo na função como gestor

\begin{tabular}{lcc|cc}
\hline \multicolumn{2}{c}{ Tempo na Organização } & \multicolumn{2}{c}{ Tempo na Função } \\
\hline \multicolumn{1}{c}{ Escala } & Respondentes & $\mathbf{\%}$ & Respondentes & \% \\
\hline Entre 1 e 9 anos & 4 & 26,7 & 8 & 53,3 \\
Entre 10 e 19 anos & 7 & 46,6 & 6 & 40,0 \\
Acima de 20 anos & 4 & 26,7 & 1 & 6,7 \\
\hline Total & $\mathbf{1 5}$ & $\mathbf{1 0 0 , 0 0}$ & $\mathbf{1 5}, 00$ \\
\hline \multicolumn{3}{r}{ Fonte: dados da pesquisa. }
\end{tabular}


Folga organizacional no processo de gestão do orçamento: um estudo no SENAC de Santa

Catarina

Nota-se na Tabela 2 que a grande maioria dos respondentes já trabalha mais de 10 anos no SENAC/SC. Porém, a maioria ocupa a função de Gestor de Unidades Operativas da Instituição a menos de 10 anos.

O perfil apresentado dos Gestores das Unidades de Negócios do SENAC pretende contribuir no sentido de indicar em que medida o respondente tem condições de compreender as práticas na gestão do orçamento. Os resultados a estas questões sugerem que os respondentes têm o perfil necessário para responder as questões do instrumento de pesquisa, especialmente em decorrência de sua formação acadêmica e anos de experiência na função.

\subsection{Estatística Descritiva dos Elementos de Folga Organizacional}

As Tabelas 3 a 5 apresentam estatísticas descritivas para análise da propensão dos gestores criar folga organizacional na gestão do orçamento. Os dados foram tabulados em planilha eletrônica e a média $(\overline{\mathbf{X}})$ e o desvio padrão $(\sigma)$ foram obtidas com o software estatístico SPSS. Os respondentes foram solicitados a apontar seu grau de concordância com cada uma das assertivas contidas no instrumento de pesquisa, em uma escala de cinco pontos, desde Discordo Totalmente (DT), Discordo Parcialmente (DP), Não tenho Opinião (NO), Concordo Parcialmente (CP) até Concordo Totalmente (CT).

As quatorze dimensões, com suas respectivas assertivas, contidas no instrumento de pesquisa foram divididas em três blocos para fins de análise: a) presença de folga organizacional no processo orçamentário; b) folga de poder dos gestores no processo orçamentário; e c) relevância do orçamento na gestão e controle das unidades de negócios. $\mathrm{Na}$ Tabela 3 apresentam-se as respostas sobre a presença de folga organizacional no processo orçamentário das unidades de negócios do SENAC de Santa Catarina. 
Tabela 3 - Estatística descritiva da presença de folga organizacional no processo orçamentário

\section{QUESTÕES}

\begin{tabular}{|l|l|l|l|l|l|l|l|}
\hline DT & DP & NO & CP & CT & T & $\bar{X}$ & $\sigma$ \\
\hline
\end{tabular}

\section{Folga do diretor da unidade na elaboração do orçamento}

1) Para se proteger, o Diretor da unidade de negócios apresenta um orçamento que pode ser facilmente alcançado

2) O Diretor da unidade de negócios estabelece 2 níveis de critérios: um entre ele mesmo e as vendas, e o outro critério entre ele e a Administração Regional, para ser cauteloso

3) Folgas no planejamento orçamentário são boas para fazer coisas que não podem ser oficialmente aprovadas

4) Em tempos favoráveis o Diretor da Unidade de Negócios concorda com a elaboração de um orçamento cujas metas sejam mais fáceis de atingir

\begin{tabular}{|l|l|l|l|l|l|l|l}
5 & 6 & 1 & 3 & 0 & 15 & 2,13 & 1,13 \\
\hline 7 & 5 & 0 & 1 & 2 & 15 & 2,07 & 1,44 \\
\hline 4 & 5 & 1 & 3 & 2 & 15 & 2,60 & 1,45 \\
\hline 3 & 4 & 1 & 6 & 1 & 15 & 2,87 & 1,36 \\
\hline
\end{tabular}

\section{Manipulação do orçamento}

5) Com alguma habilidade, o Diretor da unidade de negócios pode determinar sua performance pessoal, de acordo com seus interesses

6) Os coordenadores de núcleos são informados pelo Diretor da unidade sobre a necessidade de atingir as metas orçamentárias

\begin{tabular}{|c|c|c|c|c|c|c|c|c|}
\hline \multicolumn{9}{|l|}{ Institucionalização de folgas } \\
\hline $\begin{array}{l}\text { 7) Em períodos de crise, a área mais lucrativa em períodos } \\
\text { posteriores é menos propensa a reduzir suas folgas no planejamento } \\
\text { orçamentário que outras áreas com resultados inferiores }\end{array}$ & 1 & 3 & 2 & 9 & 0 & 15 & 3,27 & 1,03 \\
\hline $\begin{array}{l}\text { 8) O Diretor da Unidade Negócios que está no cargo por um longo } \\
\text { tempo é menos propenso a reduzir folgas orçamentárias por meio de } \\
\text { cortes dos gastos e despesas do que um Diretor que assumiu outra } \\
\text { Unidade de Negócios há pouco tempo. }\end{array}$ & 5 & 5 & 1 & 2 & 2 & 15 & 2,40 & 1,45 \\
\hline $\begin{array}{l}\text { 9) O Diretor da Unidade de Negócios com uma forte personalidade } \\
\text { será menos propenso a reduzir folgas em seu orçamento }\end{array}$ & 2 & 4 & 1 & 8 & 0 & 15 & 3,00 & 1,20 \\
\hline
\end{tabular}

\section{Detecção de folgas}

10) O Diretor da Unidade de Negócios tem informações suficientes para saber se há folga em seu planejamento orçamentário

11) A Direção Regional recebe informações detalhadas sobre as atividades da Unidade de Negócios

12) A Direção Regional tem como saber se há folga no orçamento da Unidade de Negócios

\begin{tabular}{|l|l|l|l|l|l|l|l}
0 & 2 & 0 & 7 & 6 & 15 & 4,13 & 0,99 \\
\hline 0 & 4 & 0 & 7 & 4 & 15 & 3,73 & 1,16 \\
\hline & 3 & 1 & 7 & 3 & 15 & 3,53 & 1,25 \\
\hline
\end{tabular}

Fonte: dados da pesquisa.

Observa-se na Tabela 3, que das quatro dimensões relativas à presença da folga organizacional no processo orçamentário, destaca-se com as maiores médias e os menores desvios padrões a detecção de folgas, seguida da institucionalização de folgas. Estes resultados coadunam com os de Verhagem e Beuren (2011), que aplicaram este instrumento de pesquisa em uma empresa de grande porte do estado de Santa Catarina, mas que adota sistema de remuneração variável. Denota-se que a propensão dos gestores para criar folga no orçamento independe se há ou não sistema de remuneração variável na organização.

$\mathrm{Na}$ dimensão manipulação do orçamento, a assertiva de que os coordenadores de núcleos são informados pelo diretor da unidade sobre a necessidade de atingir as metas orçamentárias obteve indicação de concordo plenamente por 14 dos 15 respondentes. Este 
Folga organizacional no processo de gestão do orçamento: um estudo no SENAC de Santa Catarina

item em particular sugere que pode haver propensão dos gestores para criar folga organizacional na gestão do orçamento para alcançar facilmente as metas orçamentárias.

Esta propensão pode ser favorecida se o gestor tiver folga de poder no processo orçamentário. Neste sentido, na Tabela 4 apresenta-se a estatística descritiva das respostas referentes a este bloco de questões.

Tabela 4 - Estatística descritiva da folga de poder dos gestores no processo orçamentário

\section{QUESTÕES}

\begin{tabular}{|l|l|l|l|l|l|l|l|} 
DT & DP & NO & CP & CT & T & $\bar{X}$ & $\sigma$ \\
\hline
\end{tabular}

\begin{tabular}{|c|c|c|c|c|c|c|c|c|}
\hline \multicolumn{9}{|l|}{ Atitude em relação ao sistema de controle da direção regional } \\
\hline $\begin{array}{l}\text { 13) A Direção Regional avalia a performance da Unidade de } \\
\text { Negócios baseada somente no atendimento das metas orçamentárias }\end{array}$ & 1 & 2 & 0 & 9 & 3 & 15 & 3,73 & 1,16 \\
\hline $\begin{array}{l}\text { 14) A Direção Regional repudia o Diretor da Unidade de Negócios } \\
\text { negligente com seu orçamento }\end{array}$ & 3 & 2 & 1 & 8 & 1 & 15 & 3,20 & 1,26 \\
\hline $\begin{array}{l}\text { 15) A Direção Regional exerce pressão para que as metas } \\
\text { orçamentárias das Unidades de Negócio aconteçam }\end{array}$ & 0 & 1 & 0 & 6 & 8 & 15 & 4,40 & 0,83 \\
\hline $\begin{array}{l}\text { 16) Se o Diretor da Unidade de Negócios falha no atendimento de } \\
\text { seu orçamento, a Direção Regional determina medidas enérgicas }\end{array}$ & 5 & 5 & 0 & 4 & 1 & 15 & 2,40 & 1,40 \\
\hline
\end{tabular}

Atitude em relação aos subordinados

17) Meus subordinados aprendem que obediência e respeito pela autoridade (Diretores/ Coordenadores) são importantes virtudes

18) Uma ordem imposta ao subordinado evita discussões e garante a execução da tarefa

19) Subordinados devem aceitar as decisões dos seus chefes incondicionalmente

20) Se as pessoas falarem menos e trabalharem mais, todos estarão em melhor situação

\section{Pressão}

21) Eu pressiono meus colaboradores para obter resultados

22) O orçamento é elaborado de modo a colocar pressão para aumentar produtividade e controle dos custos

\begin{tabular}{|l|l|l|l|l|l|l|l}
4 & 3 & 1 & 6 & 1 & 15 & 2,80 & 1,42 \\
\hline 5 & 3 & 2 & 5 & 0 & 15 & 2,47 & 1,30 \\
\hline 5 & 4 & 0 & 2 & 0 & 15 & 1,67 & 1,05 \\
\hline
\end{tabular}

\begin{tabular}{|l|l|l|l|l|l|l|l|}
\hline 3 & 1 & 0 & 9 & 2 & 15 & 3,40 & 1,40 \\
\hline 2 & 6 & 0 & 7 & 0 & 15 & 2,80 & 1,21 \\
\hline
\end{tabular}

Autonomia orçamentária

23) O orçamento é elaborado de acordo com meus interesses

24) A Direção Regional aceita o planejamento orçamentário de forma incondicional

25) Eu tenho completa autonomia em tomar decisões referentes à elaboração do orçamento da Unidade de Negócios

\begin{tabular}{|c|c|c|c|c|c|c|c}
\hline 10 & 3 & 0 & 1 & 1 & 15 & 1,67 & 1,23 \\
\hline 5 & 4 & 0 & 6 & 0 & 15 & 2,47 & 1,36 \\
\hline 2 & 4 & 0 & 8 & 1 & 15 & 3,13 & 1,30 \\
\hline
\end{tabular}

\section{Participação no orçamento}

26) Eu recebo metas da Direção Regional para usar como base na elaboração do planejamento orçamentário

27) Eu participo de reuniões gerenciais onde as discrepâncias orçamentárias são discutidas

28) A Direção Regional atende minhas solicitações para melhorar o orçamento

29) Meus interesses são levados em conta tanto quanto possível

Práticas de fiscalização do orçamento

30) A Direção Regional utiliza os números orçamentários para tomar decisões no que se refere à Unidade de Negócios 31) A Direção Regional enfatiza a redução de custos

\begin{tabular}{|l|l|l|l|l|l|l|l}
0 & 1 & 0 & 5 & 9 & 15 & 4,47 & 0,83 \\
\hline 1 & 2 & 0 & 6 & 6 & 15 & 3,93 & 1,28 \\
\hline 0 & 3 & 0 & 10 & 2 & 15 & 3,73 & 0,96 \\
\hline 4 & 3 & 1 & 5 & 2 & 15 & 2,87 & 1,51 \\
\hline
\end{tabular}

\begin{tabular}{|l|l|l|l|l|l|l|l}
0 & 3 & 0 & 7 & 5 & 15 & 3,93 & 1,10 \\
0 & 2 & 0 & 6 & 7 & 15 & 4,20 & 1,01 \\
\hline
\end{tabular}


32) A Direção Regional avalia comigo o atingimento do orçamento
da Unidade de Negócios pela qual sou responsável

\begin{tabular}{l|l|l|l|l|l|l|l|l}
\hline Atitude relativamente aos critérios \\
\hline 33) Eu prefiro elaborar um orçamento que possa ser atingido & 1 & 4 & 0 & 2 & 8 & 15 & 3,80 & 1,52 \\
\hline $\begin{array}{l}\text { 34) Os Diretores de outras Unidades de Negócios preferem elaborar } \\
\text { seus orçamentos de forma a ultrapassar o planejado, do que não } \\
\text { conseguir atingir as metas }\end{array}$ & 2 & 2 & 6 & 4 & 1 & 15 & 3,00 & 1,13 \\
\hline
\end{tabular}

Fonte: dados da pesquisa.

Verifica-se na Tabela 4, que as assertivas das dimensões autonomia orçamentária e atitude em relação aos subordinados obtiveram as menores médias, implicando pouca autonomia orçamentária, mas baixo nível de subordinação. As demais dimensões, de modo geral, apresentaram médias elevadas, o que é um indicador de existência de folga de poder no processo orçamentário. Na comparação dos resultados com a pesquisa de Verhagem e Beuren (2011), nota-se uma discrepância na dimensão atitude em relação aos subordinados, que no estudo dos autores apresentou médias mais elevadas, o que significa menor folga de poder.

A análise da presença de folga e da folga de poder no processo orçamentário é especialmente relevante se a gestão orçamentária é importante na organização. Assim, na Tabela 5 apresenta-se a estatística descritiva das respostas sobre a relevância do orçamento na gestão das unidades de negócios do SENAC.

Tabela 5 - Estatística descritiva da relevância do orçamento na gestão e controle das Unidades de Negócios QUESTÕES \begin{tabular}{|l|l|l|l|l|l|l|l|} 
DT & DP & NO & CP & CT & T & $\bar{X}$ & $\sigma$ \\
\hline
\end{tabular}

\begin{tabular}{|c|c|c|c|c|c|c|c|c|}
\hline \multicolumn{9}{|c|}{ Atitude relativamente à relevância de atingir o orçamento para avaliação } \\
\hline $\begin{array}{l}\text { 35) Recebo algum tipo de bonificação se atingir os objetivos do } \\
\text { planejamento orçamentário da minha Unidade de Negócios }\end{array}$ & 13 & 2 & 0 & 0 & 0 & 15 & 1,13 & 0,35 \\
\hline $\begin{array}{l}\text { 36) Se eu não realizar os valores orçados, a Administração Regional } \\
\text { faz questionamentos }\end{array}$ & 0 & 2 & 0 & 9 & 4 & 15 & 4,00 & 0,93 \\
\hline $\begin{array}{l}\text { 37) Na avaliação do Diretor da Unidade de Negócios, as habilidades } \\
\text { para obter resultados de seus colaboradores é considerado }\end{array}$ & 0 & 2 & 1 & 9 & 3 & 15 & 3,87 & 0,92 \\
\hline \multicolumn{9}{|l|}{ Propósito do orçamento } \\
\hline $\begin{array}{l}\text { 38) O orçamento é uma das ferramentas essenciais para a minha } \\
\text { Unidade de Negócios }\end{array}$ & 0 & 0 & 0 & 7 & 8 & 15 & 4,53 & 0,52 \\
\hline $\begin{array}{l}\text { 39) Eu acredito que tentar realizar o planejado do orçamento é como } \\
\text { um jogo }\end{array}$ & 2 & 6 & 2 & 5 & 0 & 15 & 2,67 & 1,11 \\
\hline \multicolumn{9}{|l|}{ Importância do orçamento } \\
\hline $\begin{array}{l}\text { 40) Os critérios que são estabelecidos na construção do } \\
\text { planejamento orçamentário influenciam o aumento de produtividade }\end{array}$ & 1 & 1 & 1 & 7 & 5 & 15 & 3,93 & 1,16 \\
\hline $\begin{array}{l}\text { 41) Se fosse possível eu gostaria de trabalhar com mais liberdade, } \\
\text { sem me preocupar excessivamente em realizar o plano orçamentário }\end{array}$ & 2 & 9 & 0 & 3 & 1 & 15 & 2,47 & 1,19 \\
\hline $\begin{array}{l}\text { 42) Se nenhum critério fosse estabelecido pela Administração } \\
\text { Regional, isso faria com que a performance da minha Unidade de } \\
\text { Negócios seria melhor do que tenho obtido. }\end{array}$ & 8 & 3 & 1 & 2 & 1 & 15 & 2,00 & 1,36 \\
\hline
\end{tabular}

Fonte: dados da pesquisa. 
Folga organizacional no processo de gestão do orçamento: um estudo no SENAC de Santa Catarina

Nota-se na Tabela 5, que as notas atribuídas pelos respondentes para as assertivas das três dimensões, de modo geral, são elevadas, demonstrando a relevância da gestão orçamentária na organização. Esta relevância é confirmada na média mais baixa atribuída para a seguinte assertiva: se nenhum critério fosse estabelecido pela administração regional, isso faria com que a performance da minha unidade de negócios seria melhor do que tenho obtido.

Ressalta-se que a assertiva "recebo algum tipo de bonificação se atingir os objetivos do planejamento orçamentário na minha unidade de negócios", obteve discordância total de 13 dos 15 respondentes e dois respondentes discordaram parcialmente, com média de 1,13, o que indica não existir um sistema de recompensa variável para os gestores na organização.

Depreende-se, na comparação das médias das assertivas de cada dimensão com a pesquisa de Verhagem e Beuren (2011), que o sistema de recompensa variável para os gestores não foi determinante da propensão de criar folga organizacional no processo de gestão do orçamento. Todavia, como as médias ponderadas oscilaram entre 1,13 e 4,53 e os desvios padrões entre 0,35 e 1,52 nas respostas relativamente à propensão de criar folga organizacional no processo de gestão do orçamento, além da grande quantidade de questões para analisar, considerou-se mais apropriado utilizar uma técnica de análise multivariada.

\subsection{Aplicação do Alfa de Cronbach}

Antes da análise multivariada propriamente dita, verificou-se a confiabilidade dos dados por meio do alfa de Cronbach. Assim fez-se a análise individualizada, de cada um dos fatores e a geral, com todos os elementos ao mesmo tempo, conforme Tabela 6.

Tabela 6 - Alfa de Crombach de cada fator e do conjunto de elementos do processo de gestão do orçamento

\begin{tabular}{|c|c|c|}
\hline Dimensão & Descrição & $\alpha$ Cronbach \\
\hline Fator 1 & Folga do diretor da unidade na elaboração do orçamento & 0,5827 \\
\hline Fator 2 & Manipulação do orçamento & 0,8071 \\
\hline Fator 3 & Institucionalização de folgas & 0,6888 \\
\hline Fator 4 & Detecção de folgas & 0,5248 \\
\hline Fator 5 & Atitude em relação ao sistema de controle da direção regional & 0,7747 \\
\hline Fator 6 & Atitude em relação aos subordinados & 0,6039 \\
\hline Fator 7 & Pressão & 0,7083 \\
\hline Fator 8 & Autonomia orçamentária & 0,8031 \\
\hline Fator 9 & Participação no orçamento & 0,7131 \\
\hline Fator 10 & Práticas de fiscalização do orçamento & 0,8730 \\
\hline Fator 11 & Atitude relativamente aos critérios & 0,5039 \\
\hline Fator 12 & Atitude relativamente à relevância de atingir o orçamento para avaliação & 0,8650 \\
\hline Fator 13 & Propósito do orçamento & 0,5164 \\
\hline Fator 14 & Importância do orçamento & 0,8708 \\
\hline
\end{tabular}

Fonte: dados da pesquisa.

REAd I Porto Alegre - Edição 75 - Nº 2 - maio/agosto 2013 - p. 274-300 
Observa-se na Tabela 6, que tanto os elementos analisados individualmente quanto em conjunto, indicam confiabilidade superior a 0,5. De acordo com Nunnaly e Bernstein (1994) e Hair Jr. et al. (2009), o valor de 0,75 é considerado aceitável, indicando uma boa confiabilidade acerca do instrumento de coleta e dos dados levantados. Os fatores de maior confiabilidade são os de números $1,5,8,10,12$ e 14; no outro extremo estão os de números 1 , 4, 6, 11 e 13; e como fatores com confiabilidade mediana constam os de números 3 , 7 e 9 .

Denota-se que o grau de confiabilidade de cada fator não está atrelado ao bloco de dimensões a que ele pertence, uma vez que nas dimensões dos três blocos foram encontrados fatores com confiabilidade maior, mediana e menor. Embora nem todos tenham alcançado o valor de 0,75 , mas todos apresentam confiabilidade superior a 0,5 .

\subsection{Análise Fatorial}

$\mathrm{Na}$ análise fatorial, inicialmente foi feito um mapa fatorial exploratório, para identificar os elementos de folga orçamentária que possam caracterizar o objeto de estudo. A Análise Fatorial Exploratória (AFE) busca o agrupamento de variáveis conforme suas correlações. Esta técnica objetiva a conjunção de variáveis que possuem um grupo particular de características, semelhantes e correlacionadas entre si.

Ainda que haja correlações entre todas as variáveis em estudo, na AFE a variável que participa de um determinado fator vai possuir forte correlação com as variáveis deste fator, dentro do próprio grupo, e correlações fracas com as variáveis pertencentes aos outros fatores, intergrupos. Depreende-se que os grupos que formam cada um dos fatores representam um conceito que será formado pelo fator de construção subjacente aos propósitos do estudo.

O principal objetivo da utilização de uma ferramenta multivariada como a AFE é o resumo e redução de dados de análise. Em estudos com uma quantidade muito grande de dados, a economia se torna uma variável que proporciona eficiência ao trabalho.

\subsubsection{Cargas Fatoriais}

O instrumento de pesquisa, composto por 42 asserções, foi dividido inicialmente em 14 fatores, compreendendo cada um várias questões, conforme apresentado na Tabela 7. Também se destacam a comunalidade e a carga fatorial de cada um dos fatores. Conforme Hair et al. (2009), comunalidade é a quantia total de variância que uma variável original compartilha com todas as outras variáveis incluídas na análise. 
Folga organizacional no processo de gestão do orçamento: um estudo no SENAC de Santa

Catarina

Tabela 7 - Cargas fatoriais das questões do instrumento de pesquisa

\begin{tabular}{|c|c|c|c|c|}
\hline Dimensão & Questões & Comunalidade & Carga & Nome \\
\hline \multirow{4}{*}{ Fator 1} & Q1 & 0,752 & 0,867 & \multirow{4}{*}{$\begin{array}{l}\text { Folga do diretor da unidade na } \\
\text { elaboração do orçamento }\end{array}$} \\
\hline & Q2 & 0,475 & 0,689 & \\
\hline & Q3 & 0,634 & 0,796 & \\
\hline & Q4 & 0,071 & 0,267 & \\
\hline \multirow{2}{*}{ Fator 2} & Q5 & 0,759 & 0,576 & \multirow{2}{*}{ Manipulação do orçamento } \\
\hline & Q6 & 0,759 & 0,576 & \\
\hline \multirow{3}{*}{ Fator 3} & Q7 & 0,607 & 0,779 & \multirow{3}{*}{ Institucionalização de folgas } \\
\hline & Q8 & 0,651 & 0,807 & \\
\hline & Q9 & 0,612 & 0,782 & \\
\hline \multirow{3}{*}{ Fator 4} & Q10 & 0,491 & 0,241 & \multirow{3}{*}{ Detecção de folgas } \\
\hline & Q11 & 0,835 & 0,697 & \\
\hline & Q12 & 0,782 & 0,612 & \\
\hline \multirow{4}{*}{ Fator 5} & Q13 & 0,138 & 0,372 & \multirow{4}{*}{$\begin{array}{l}\text { Atitude em relação ao sistema de } \\
\text { controle da direção regional }\end{array}$} \\
\hline & Q14 & 0,778 & 0,882 & \\
\hline & Q15 & 0,574 & 0,757 & \\
\hline & Q16 & 0,819 & 0,905 & \\
\hline \multirow{4}{*}{ Fator 6} & Q17 & 0,304 & 0,551 & \multirow{4}{*}{ Atitude em relação aos subordinados } \\
\hline & Q18 & 0,684 & 0,827 & \\
\hline & Q19 & 0,709 & 0,842 & \\
\hline & Q20 & 0,332 & 0,576 & \\
\hline \multirow{2}{*}{ Fator 7} & Q21 & 0,736 & 0,858 & \multirow{2}{*}{ Pressão } \\
\hline & Q22 & 0,736 & 0,858 & \\
\hline \multirow{3}{*}{ Fator 8} & Q23 & 0,561 & 0,749 & \multirow{3}{*}{ Autonomia orçamentária } \\
\hline & Q24 & 0,791 & 0,889 & \\
\hline & Q25 & 0,784 & 0,885 & \\
\hline \multirow{4}{*}{ Fator 9} & Q26 & 0,105 & 0,324 & \multirow{4}{*}{ Participação no orçamento } \\
\hline & Q27 & 0,618 & $-0,786$ & \\
\hline & Q28 & 0,060 & 0,245 & \\
\hline & Q29 & 0,610 & 0,781 & \\
\hline \multirow{3}{*}{ Fator 10} & Q30 & 0,913 & 0,955 & \multirow{3}{*}{ Práticas de fiscalização do orçamento } \\
\hline & Q31 & 0,811 & 0,901 & \\
\hline & Q32 & 0,709 & 0,842 & \\
\hline \multirow{2}{*}{ Fator 11} & Q33 & 0,521 & 0,722 & \multirow{2}{*}{ Atitude relativamente aos critérios } \\
\hline & Q34 & 0,521 & 0,722 & \\
\hline \multirow{3}{*}{ Fator 12} & Q35 & 0,333 & 0,577 & \multirow{3}{*}{$\begin{array}{l}\text { Atitude relativamente à relevância de } \\
\text { atingir o orçamento para avaliação }\end{array}$} \\
\hline & Q36 & 0,623 & 0,789 & \\
\hline & Q37 & 0,409 & 0,640 & \\
\hline \multirow{2}{*}{ Fator 13} & Q38 & 0,728 & 0,853 & \\
\hline & Q39 & 0,728 & 0,853 & Propósito do orçamento \\
\hline & Q40 & 0,773 & $-0,879$ & \\
\hline Fator 14 & Q41 & 0,501 & 0,708 & Importância do orçamento \\
\hline & Q42 & 0,838 & 0,915 & \\
\hline
\end{tabular}

Fonte: dados da pesquisa.

As questões Q4, Q10, Q13, Q26 e Q28, dos fatores 1, 4, 5 e 9, respectivamente, foram retiradas da análise dos dados, pois as suas cargas fatoriais ficaram abaixo de 0,40, em decorrência da baixa significância e comunalidade. Em outras palavras, como estes fatores possuem graus baixos de comunalidade, não conseguem explicar a existência de folga organizacional no processo orçamentário. 
Verifica-se ainda na Tabela 7, que o Fator 2, Manipulação do Orçamento, e o Fator 10, Práticas de Fiscalização do Orçamento possuem graus altos de comunalidade, significando que estes fatores podem explicar a existência de folga organizacional no processo orçamentário mais do que os outros fatores.

O Fator 2 determina que os gestores das unidades de negócio elaboram o orçamento como forma de se autoproteger. Onsi (1973) destacou em seus achados que os gestores aproveitam as oportunidades para construir folga e que a criação de folga, como medida de auto-proteção, parece ser uma característica do gestor. A propensão para criar folga organizacional no processo orçamentário pode ser atribuída ao auto-interesse dos gestores respondentes da pesquisa, que buscam com este artifício demonstrar um melhor desempenho em suas unidades de negócios.

As elevadas comunalidades constatadas no fator 10 , que se refere às práticas de fiscalização do orçamento, denotam que a direção regional utiliza os números orçamentários para tomar decisões no que se refere às unidades de negócios, que a gestão de custos é fundamental nas práticas orçamentárias e que avalia o cumprimento do orçamento da unidade de negócio juntamente com o gestor.

Os Fatores 1 a 4 indicam presença de folga organizacional no processo orçamentário, principalmente no Fator 4 (detecção de folgas), ainda que este seja o bloco com as dimensões que não possuem as maiores comunalidades nas respectivas questões. O Fator 2 (manipulação do orçamento) indica que há propensão de criar folga nos orçamentos, uma vez que os gestores preferem apresentar orçamentos que podem ser mais facilmente alcançados. Escolher um padrão facilmente atingível permite proteção frente às incertezas no ambiente operacional.

A existência de folga de poder no processo orçamentário dos gestores das unidades de negócios é observada nos Fatores 5 a 11, cujo bloco de dimensões possui as maiores comunalidades nas respectivas questões, destacando-se as do Fator 10. O bloco com as dimensões relativas à relevância do orçamento na gestão e controle das unidades de negócios revela as maiores comunalidades nas questões da dimensão propósito do orçamento (Fator 13)

\subsubsection{Correlações entre os Fatores de Gestão Orçamentária}

$\mathrm{Na}$ análise da matriz de correlações constante na Tabela 8, observam-se os elementos que melhor se relacionam. 
Folga organizacional no processo de gestão do orçamento: um estudo no SENAC de Santa

Catarina

Tabela 8 - Correlações entre os fatores de gestão orçamentária

\begin{tabular}{|c|c|c|c|c|c|c|c|c|c|c|c|c|c|c|}
\hline & $\begin{array}{c}\text { FAT } \\
1\end{array}$ & $\begin{array}{c}\text { FAT } \\
2\end{array}$ & $\begin{array}{c}\text { FAT } \\
3\end{array}$ & $\begin{array}{c}\text { FAT } \\
4\end{array}$ & $\begin{array}{c}\text { FAT } \\
5\end{array}$ & $\begin{array}{c}\text { FAT } \\
6\end{array}$ & $\begin{array}{c}\text { FAT } \\
7\end{array}$ & $\begin{array}{c}\text { FAT } \\
8\end{array}$ & $\begin{array}{c}\text { FAT } \\
9\end{array}$ & $\begin{array}{c}\text { FAT } \\
10\end{array}$ & $\begin{array}{c}\text { FAT } \\
11\end{array}$ & $\begin{array}{c}\text { FAT } \\
12\end{array}$ & $\begin{array}{c}\text { FAT } \\
13\end{array}$ & $\begin{array}{c}\text { FAT } \\
14\end{array}$ \\
\hline FAT 1 & 1 &, 046 &, 100 &,- 102 &,- 184 &,- 205 &,$- 621^{*}$ &, 195 &,- 016 &, 154 & ,201 &, 135 &, 104 & ,255 \\
\hline FAT 2 & & 1 & ,249 &,- 485 &,- 145 &, $623^{*}$ &,- 170 & ,461 & ,300 &,- 429 &, 141 &,- 383 &,- 153 & ,249 \\
\hline FAT 3 & & & 1 &,$- 569^{*}$ &,- 133 &, $617^{*}$ &,- 362 &, 185 &, 017 &,- 240 &,- 016 &,- 292 &,- 112 & ,211 \\
\hline FAT 4 & & & & 1 &, $573^{*}$ & $660^{* *}$ &, 160 &,- 374 & , 106 & $683^{* *}$ & ,329 &, $647^{* *}$ & ,360 &,- 382 \\
\hline FAT 5 & & & & & 1 &,- 169 &, 151 &,- 205 &,- 150 &, 315 &, 024 &, $568^{*}$ & ,061 &,- 071 \\
\hline FAT 6 & & & & & & 1 &,- 012 & ,465 &, 191 &,- 492 &,- 067 &,- 271 &,- 078 &,- 023 \\
\hline FAT 7 & & & & & & & 1 &, 140 &, 013 &,- 424 &,- 257 &,- 221 &,- 191 &,- 425 \\
\hline FAT 8 & & & & & & & & 1 & ,093 &, $695^{* *}$ & ,037 &,- 339 &,- 146 &,- 113 \\
\hline FAT 9 & & & & & & & & & 1 &, 163 & ,073 &,- 147 &,- 127 &,- 343 \\
\hline FAT 10 & & & & & & & & & & 1 & ,404 &, $756^{* *}$ &, $538^{*}$ &,- 133 \\
\hline FAT 11 & & & & & & & & & & & 1 &, 484 &, $864^{* *}$ &,- 254 \\
\hline FAT 12 & & & & & & & & & & & & 1 &, $719^{* *}$ &,- 209 \\
\hline FAT 13 & & & & & & & & & & & & & 1 &,- 310 \\
\hline FAT 14 & & & & & & & & & & & & & & 1 \\
\hline
\end{tabular}

Fonte: dados da pesquisa.

Conforme Tabela 8, os elementos assinalados com um e dois asteriscos, respectivamente, possuem correlação moderada e forte. Segundo Barbeta (2010, p. 251), “o valor de $\mathbf{r}$ será tão mais próximo de $\mathbf{1}$ (ou -1) quanto mais forte for a correlação nos dados observados". O $\mathbf{r}^{2}$ é a "medida da proporção da variância da variável dependente em torno de sua média que é explicada pelas variáveis independentes ou preditoras" (HAIR et al., 2009, p. 139).

Considerando que quanto mais próximo de 1 , maior o poder de explicação da equação proposta, Loesch e Hoeltgebaum (2005) indicam o exposto na Tabela 9.

Tabela 9 - Intervalos do coeficiente de determinação do $\mathrm{r}^{2}$

\begin{tabular}{cc}
\hline Intervalo & Correlação \\
\hline $0 \leq \mathrm{r}^{2}<0,30$ & fraca \\
$0,30 \leq \mathrm{r}^{2}<0,60$ & moderada \\
$0,60 \leq \mathrm{r}^{2}<0,90$ & Forte \\
$0,90 \leq \mathrm{r}^{2} \leq 1,00$ & Muito forte \\
\hline
\end{tabular}

Fonte: adaptado de Loesch; Hoeltgebaum (2005).

A maior correlação observada encontra-se entre os Fatores 11, Atitude relativamente aos critérios, e 13, Propósito do orçamento. Tal evidencia a propensão dos gestores para criar folga, dada a relevância do orçamento na gestão das unidades de negócios. Subjacente está o conflito de interesses entre principal e agente e a assimetria de informações entre ambos. $\mathrm{O}$ agente prefere elaborar um orçamento que possa ser facilmente atingido, assim sua unidade de negócio apresentará melhor desempenho.

REAd I Porto Alegre - Edição 75 - Nº 2 - maio/agosto 2013 - p. 274-300 
Ilse Maria Beuren \&Paulo Wienhage

\subsubsection{Matriz Fatorial}

$\mathrm{Na}$ matriz fatorial, as 14 dimensões que compõem o questionário, com suas respectivas assertivas, foram reduzidas para 8 dimensões, conforme o estudo de Onsi (1973):

a) atitude - variáveis que indicam a atitude dos gestores em relação a folga, questões do Fator 1;

b) manipulação - varáveis que indicam como o gerente cria e usa a folga, questões do Fator 2;

c) institucionalização - variáveis que fazem o gestor menos propenso a reduzir sua folga, questões do Fator 3;

d) detecção de folga - variáveis que indicam as capacidades do superior para detectar a folga baseado no valor das informações que ele recebe, questões do Fator 4;

e) atitude em relação ao sistema de controle da alta administração - variáveis que indicam uma filosofia autoritária em relação ao orçamento, sendo atribuída pela alta administração aos gestores divisionais, questões do Fator 5;

f) atitude em relação ao sistema de controle divisional - variáveis sobre as atitudes em relação aos subordinados, recursos de pressão, autonomia de orçamento, participação no orçamento, supervisão no uso do orçamento, questões dos Fatores $6,7,8,9$ e 10

g) atitudes em relação ao orçamento - variáveis sobre atitudes em relação ao nível de padronização, atitude em relação a relevância da realização do orçamento para avaliação do desempenho, e atitude dos gestores (positiva ou negativa) em relação ao sistema orçamentária em geral, como uma ferramenta gerencial, questões dos Fatores 11, 12 e 13; e

h) relevância do orçamento - variáveis que indicam as atitudes do gestor em relação a relevância de padrões às operações do seu departamento, questões do Fator 14.

Nesta análise consideraram-se dois fatores para explicar a propensão dos gestores das unidades de negócios do SENAC para criarem folga na elaboração do orçamento. Na Tabela 10 evidenciam-se os elementos e suas respectivas cargas fatoriais. 
Folga organizacional no processo de gestão do orçamento: um estudo no SENAC de Santa Catarina

Tabela 10 - Matriz Fatorial das dimensões agrupadas

\begin{tabular}{|c|c|c|}
\hline Dimensões/Elementos & Fator 1 & Fator 2 \\
\hline Atitude (E1) & ,191 & ,726 \\
\hline Manipulação (E2) & 652 &,- 367 \\
\hline Institucionalização (E3) & 663 &,- 111 \\
\hline Detecção de folga (E4) &,- 913 &,- 013 \\
\hline Atitude em relação ao sistema de controle da alta administração (E5) &,- 512 &,- 228 \\
\hline Atitude em relação ao sistema de controle divisional (E6) & 043 &,- 762 \\
\hline Atitude em relação ao orçamento ( E7) &,- 359 & ,454 \\
\hline Relevância do orçamento (E8) &, 559 & ,430 \\
\hline
\end{tabular}

Fonte: dados da pesquisa.

As cargas fatoriais constantes na Tabela 10 apontam como integrantes do Fator 1 os elementos Manipulação (E2), Institucionalização (E3), Detecção de Folga (E4), Atitude em relação ao sistema de controle da alta administração (E5) e Relevância do orçamento (E8). No Fator 2 observam-se os elementos Atitude (E1), Atitude em relação ao sistema de controle divisional (E6) e Atitude em relação ao orçamento (E7).

As dimensões elencadas no Fator 1 destacam o comportamento de gestores que não incluem folgas na elaboração do orçamento. Ressalta-se na análise fatorial exploratória o elemento Detecção de folga (E4). Esta dimensão determina que o diretor da unidade de negócios tem informações suficientes para saber se há folga em seu planejamento orçamentário, assim como determina que a direção regional recebe informações detalhadas sobre as atividades da unidade de negócios e consegue saber se há folga no orçamento da unidade de negócios.

O comportamento dos gestores do Fator 2 determina que estes preferem elaborar um orçamento que possa ser atingido, mesmo não havendo nenhum tipo de bonificação se atingir as metas orçamentárias. Destaca-se na análise fatorial exploratória o elemento Atitude em relação ao sistema de controle divisional (E6), cujas variáveis contemplam as atitudes do gestor em termos de folga organizacional no processo orçamentário em relação aos subordinados, recursos de pressão, autonomia de orçamento, participação no orçamento, supervisão no uso do orçamento.

Onsi (1973) identificou que a folga orçamentária é decorrente do estilo do próprio sistema. $\mathrm{O}$ autor sugere que, se o orçamento é a base para a remuneração e avaliação dos dirigentes há uma tendência maior para se construir as folgas, pois participação nos resultados reduz a criação de folgas orçamentárias. Na empresa objeto de estudo não há sistema de remuneração variável de executivos, portanto, se esperaria que não houvesse propensão para criar folga organizacional no processo orçamentário pelos gestores das unidades de negócios. 
Uma alternativa mais plausível pode ser encontrada na pesquisa de Verhagem e Beuren (2011), realizada em uma empresa de grande porte com sistema de remuneração variável. Os autores constataram indícios de propensão dos gestores criar folga organizacional na gestão do orçamento, especialmente nos casos com desempenho inferior no alcance das metas orçamentárias.

Desse modo, na presente pesquisa a propensão para os gestores criar folga pode ser consequência da relevância do orçamento na gestão e controle das unidades de negócios. Se o gestor elaborar o orçamento com folga, mais facilmente alcançará as metas orçamentárias estabelecidas e melhor será a avaliação de desempenho de sua unidade de negócio

\section{CONSIDERAÇÃOES FINAIS}

Este estudo objetivou identificar a propensão de criar folga organizacional no processo de gestão do orçamento pelos Gestores das Unidades de Negócios do SENAC de Santa Catarina. Embora o orçamento no SENAC não seja elaborado de acordo com os interesses particulares dos seus gestores e os critérios estabelecidos na construção do planejamento orçamentário focalizem o aumento da produtividade de cada unidade de negócios e da instituição como um todo, os resultados da pesquisa sinalizam comportamentos dos gestores propensos à criação de folga orçamentária nas Unidades de Negócios pesquisadas.

Observou-se na análise das respostas que os Gestores das Unidades de Negócios do SENAC/SC elaboram orçamentos cujas metas orçamentárias são mais fáceis de serem atingidas. Também foi possível averiguar que os Gestores das Unidades de Negócios que estão no cargo mais tempo são tão propensos a criar folgas orçamentárias quanto os que assumiram a função há pouco tempo.

Mesmo sendo o processo de gestão do orçamento descentralizado, há pressão por parte da Administração Regional do SENAC/SC no que concerne ao cumprimento das metas por parte das Unidades de Negócios. Desse modo, os gestores precisam prestar contas mensalmente, por meio de reuniões gerenciais, em que as discrepâncias orçamentárias são discutidas e justificadas junto a Administração Geral. Isso pode levar a uma tendência maior para se construir as folgas orçamentárias.

O SENAC não remunera seus gestores com base nos resultados, o que por si só já não motivaria a criação de folga orçamentária. Onsi (1973), em pesquisa com 32 gerentes de 5 multinacionais americanas identificou um sistema de controle orçamentário autoritário, fruto da pressão exercida pela avaliação de desempenho. A folga identificada nesta pesquisa pode ser motivada com este mesmo propósito, já que na análise fatorial exploratória o elemento 
Folga organizacional no processo de gestão do orçamento: um estudo no SENAC de Santa

Catarina

com maior carga foi Atitude em relação ao sistema de controle divisional (E6). Nesta dimensão, as variáveis contemplam as atitudes do gestor em termos de folga organizacional no processo orçamentário em relação aos subordinados, recursos de pressão, autonomia de orçamento, participação no orçamento e supervisão no uso do orçamento.

Assim conclui-se com base nos resultados desta pesquisa que há propensão para criar folga no processo de gestão do orçamento pelos gestores das unidades de negócios do SENAC de Santa Catarina. De modo semelhante a pesquisa realizada por Onsi (1973), os motivos para a criação de folga orçamentária decorrem do interesse dos gestores em apresentar desempenho superior em relação ao previsto no orçamento. Como sugestão para futuras pesquisas, recomenda-se estudos que busquem identificar a folga organizacional no processo orçamentário de outras empresas que não remuneram os seus dirigentes com base nos resultados orçamentários e alcance de metas de resultados.

\section{REFERÊNCIAS}

ATKINSON, A.A.; BANKER, R.D.; KAPLAN, R.S.; YOUNG, S.M. Contabilidade gerencial. 3 ed. São Paulo: Atlas, 2011.

BAIMAN, S.; LEWIS, B.L. An experiment testing the behavioral equivalence of strategically equivalent employment contracts. Journal of Accounting Research, v. 27, n. 1, p. 1-20, 1981.

BARBETA, P.A. Estatística aplicada às ciências sociais. 10 ed. Florianópolis: Edufsc, 2010.

BOURGEOIS, L.J. On the measurement of organizational slack. Academy of Management Review. v. 6, n. 1. p. 29-39, 1981.

BRAGA, R. Fundamentos e técnicas de administração financeira. São Paulo: Atlas, 1995.

CERVO, A.L.; BERVIAN, P.A. Metodologia científica. 5 ed. São Paulo: Pearson Prentice Hall, 2006. 
Ilse Maria Beuren \&Paulo Wienhage

CHENG, J.; KESNER, I.F. Organizational slack and response to environmental shifts: the impact of resource allocation patterns. Journal of Management, v. 23, p. 1-18, 1997.

CYERT, R.M.; MARCH, J.G. A behavioral theory of the firm. Englewood Cliffs, NJ: Prentice Hall, 1963.

DIMMICK, D., MURRAY, V.V. Correlates of substantive policy decisions in organizations: the case of human resource management, Academy of Management Journal, v. 21 p. 611623, 1978.

DUNK, A. S. The effect of budget emphasis and information asymmetry on the relation between budgetary participation and slack. The Accounting Review, v. 68, p. 400-410, 1993.

GEIGER, S.W.; CASHEN, L.H. A multidimensional examination of slack and its impact on innovation. Journal of Managerial Issues, v. 14, n. 1, p. 68-84, 2002.

GIL, A.C. Métodos e técnicas de pesquisa social. 6. ed. São Paulo: Atlas, 2008.

HAIR, J.F.; BLACK, W.C; BABIN, B.J.; ANDERSON, R.E.; TATHAM, R.L. Análise multivariada de dados. Traduzido por Adonai Schlup Sant'Anna e Anselmo Chaves Neto. 6. ed. Porto Alegre: Bookman, 2009.

HEROLD, D.; JAYARAMAN, N.; NARAYANASWAMY, C.R. What is the relationship between organizational slack and innovation. Journal of Managerial Issues, v. 18, n. 3, p. 372-392, 2006.

INDJEJIKIAN, R.J.; MATEJKA, M. Organizational Slack in decentralized firms: the role of business unit controllers. The Accounting Review. v. 81, n.04, p. 849-872, 2006.

ISHISAKI, N. A utilização do orçamento empresarial: um estudo em empresas da região do Vale do Paraíba - SP. Dissertação (Mestrado em Administração) - Universidade de Taubaté, Taubaté, 2003.

JUNQUEIRA, E.R.; OYADOMARI, J.C.T.; MORAES, R.O. Reservas orçamentárias: um ensaio sobre os fatores que levam à sua constituição. ConTexto, Porto Alegre, v. 10, n. 17, p. $31-42,1^{\circ}$ semestre, 2010. 
Folga organizacional no processo de gestão do orçamento: um estudo no SENAC de Santa

Catarina

LIMA, A.F. Estudo da relação casual entre os níveis organizacionais de folga, o risco e o desempenho financeiro de empresas manufatureiras. Dissertação (Mestrado em Administração) - Universidade Presbiteriana Mackenzie, São Paulo, 2008.

LINN, G.; CASEY, K.M.; JOHNSON, G.H.; ELLIS, T. S. Do broad scope managerial accounting systems moderate the effects of budget emphasis, budget participation and perceived environmental uncertainty on the propensity to create budgetary slack? The Journal of Computer Information Systems, v. 42, n. 1, p. 90-96, 2001.

LOESCH, C.; HOELTGEBAUM, M. Métodos estatísticos multivariados aplicados à economia de empresas. Blumenau: Nova Letra, 2005.

LÓPEZ, M.A.L.; STAMMERJOHAN, W.W.; MCNAIR, F.M. Differences in the role of jobrelevant information in the budget participation-performance relationship among US and Mexican managers: a question of culture or communication. Journal of Management Accounting Research, v. 19, p. 105-136, 2007.

LUKKA, K. Budgetary biasing in organizations: theoretical framework and empirical evidence. Accounting, Organizations and Society, v. 13, n. 3, p. 281-301, 1988.

MAROCO, J. Análise estatística com utilização do SPSS. Lisboa: Sílabo, 2003.

MERCHANT, K.A. Budgeting and the propensity to create slack. Accounting, Organizatrions and Society, v. 10, p. 201-210, 1985.

NASCIMENTO, A.R.; RIBEIRO, D.C.; JUNQUEIRA, E.R. Estado da arte da abordagem comportamental da contabilidade gerencial: análise das pesquisas internacionais. In: CONGRESSO USP DE CONTROLADORIA E CONTABILIDADE, 8., 2008, São Paulo. Anais ... São Paulo: FEA/USP, 2008.

NASCIMENTO, A.R. Avaliação do orçamento como instrumento de controle de gestão: um estudo de caso em uma indústria de fertilizantes. In: SIMPEP, 12., 2006, Bauru/SP. Anais ... Bauru/SP, 2006.

NOHRIA, N.; GULATI, R. Is slack good or bad for innovation? Academy of Management Journal. v. 39, n. 5, p. 1245-1264, 1996. 
Ilse Maria Beuren \&Paulo Wienhage

OLIVEIRA, L.B.; ÁVILA, M.G. Descentralização em unidades de negócio: o caso de uma empresa do setor financeiro. Revista de Administração Contemporânea, v. 3, p. 127-146, 1999.

ONSI, M. Factor analysis of behavioral variables affecting budgetary slack. The Accounting Review, v. 48, n. 3, p. 535-548, 1973.

PENROSE, E. The theory of the growth of the firm. Oxford: Oxford University Press, 1959.

RIAHI-BELKAOUI, A. Organizational and budgetary slack. Westport, Conn: Quorum Books, 1994.

RICHARDSON, R.J. Pesquisa Social: métodos e técnicas. 2. ed. São Paulo: Atlas, 1989.

RUST, K.G. KATZ, J.P. Organizational slack and performance: the interactive role of workforce changes. Indianapolis, Indiana, Published in the Proceedings Midwest Academy of Management Conference, 2002.

SENAC. SC. Relatório de gestão 2009. Disponível em: <http://www.senac.org.br>. Acesso em: 12 jun. 2010.

SENDER, G. O papel da folga organizacional nas empresas: um estudo em bancos brasileiros. Dissertação (Mestrado em Administração) - Universidade Federal do Rio de Janeiro, Instituto COOPEAD de Administração, Rio de Janeiro, 2004.

SCHIFF, M.; LEWIN A.Y. The impact of people on budgets. The Accounting Review, v. 70, p. 259-268, 1970.

SINGH, J.V. Performance, slack and, risk taking in organizational decision making. Academy of Management Journal. v. 29, n. 3, p. 562-585, 1986.

STALEY, A. B.; MAGNER, N.R. Budgetary fairness, supervisory trust, and the propensity to create budgetary slack: testing a social exchange model. Accountig Behavorial Research, v. 10, p. 159-182, 2007. 
Folga organizacional no processo de gestão do orçamento: um estudo no SENAC de Santa

Catarina

STEVENS, D.E. The effects of reputation and ethics on budgetary slack. Journal of Management Accounting Research, v. 14, p. 153-171, 2002.

TUNG, N.H. Orçamento empresarial no Brasil: para empresas industriais e comerciais. 3. ed. São Paulo: Edições Universidade-empresa Ltda, 1983.

VERHAGEM, J.A.; BEUREN, I.M. Folga organizacional no processo orçamentário versus remuneração variável: o caso de uma empresa de grande porte do Sul do Brasil. In: EnGPR, 2011, João Pessoa/PB. Anais... Rio de Janeiro: ANPAD, 2011.

WELSCH, G.A. Orçamento empresarial. 4 ed. São Paulo: Atlas, 1983.

WU, E.C. Convergence of attitudes in different cultures toward the budgeting process. Journal of Business \& Management. v. 11, n. 2, p. 29-47, 2006.

YOUNG, S.M. Participative budgeting: the effects of risk aversion and asymmetric information on budgetary slack. Journal of Accounting Research, v. 23, n. 2, p. 829-842, 1985. 